\title{
Impact Measurement of a Collaborative Pathology Network and Its Digital Support
}

\author{
Paolo LOCATELLI, Federica CIRILLI ${ }^{1}$ and Fabio CHIODINI \\ Fondazione Politecnico di Milano, Piazza Leonardo da Vinci 32, 20133, Milan, Italy
}

\begin{abstract}
The possibility to access healthcare fairly and equally among all the patients can be enhanced with the development of collaborative networks. To achieve their goals and exchange relevant information, they must be combined with a proper digital support. Several works dealing with this aspect can be found in literature; however, works defining a general methodological approach to design a digital solution for a collaborative network were not found. In addition to this, to assess the impact of a pathology network and its digital support, and ensure quality improvement as well as proper clinical outcomes, a suitable panel of key performance indicators (KPIs) should be designed. This paper describes a methodology to design a digital support of a collaborative pathology network, together with a set of KPIs to assess the impact of the pathology network and its digital solution. This approach was specifically applied for the Italian Rare Cancer Network in the context of the project "Italian Rare Cancer Network: Process monitoring and System Impact Assessment”.
\end{abstract}

Keywords. Collaborative pathology networks, digital healthcare, teleconsultation, rare cancer

\section{Introduction}

The possibility to access healthcare fairly and equally among all the patients can be enhanced with the development of collaborative networks. This kind of organization allows the sharing of expertise and resources throughout a community (e.g., in a Region or in a Country). Collaborative networks are often focused on a single disease or a group of similar diseases $[1,2]$.

To achieve their goals and exchange relevant information, they must be combined with a proper digital support [2]. Several works dealing with this aspect can be found in literature: some of them describe a specific tool designed for a collaborative network [3, 4], others are related to the methodologies and architectural models to design and implement a generic health information system $[5,6]$. However, works defining a general methodological approach to design a digital solution for a collaborative network were not found. In addition to this, to assess the impact of a pathology network and its digital support, and ensure quality improvement as well as proper clinical outcomes, a suitable panel of key performance indicators (KPIs) should be designed [7, 8].

This paper describes a methodology to design a digital support of a collaborative pathology network, together with a set of KPIs to assess the impact of the pathology network and its digital solution. Then, this approach was specifically applied for the

${ }^{1}$ Corresponding Author, Federica CIRILLI, Fondazione Politecnico di Milano, Piazza Leonardo da Vinci 32, 20133, Milan, Italy; Email: federica.cirilli@fondazione.polimi.it. 
Italian Rare Cancer Network in the context of the project "Italian Rare Cancer Network: Process monitoring and System Impact Assessment", funded by the Italian Ministry of Health. However, we believe it can be applied to any collaborative pathology network.

\section{Methodological Approach and KPI Model}

The proposed approach to design a digital support of a collaborative pathology network and monitor the related impact is based on Business Process Reengineering (BPR) methodology [9], and was already described in a previous paper [10]. It is composed of six steps (figure 1):

(1) Analysis of the AS-IS process to manage patients affected by the particular disease and the related digital support for hubs and spokes cooperating within the network;

(2) Mapping of the process using Business Process Modeling Notation (BPMN) [11] in order to get a general overview of actors and actions involved;

(3) Identification of critical or weak points of the as-is process, with the purpose to define possible organizational and/or technological improvements;

(4) Definition of network needs based on the analysis of the previous point, including both organizational aspects and requirements for the digital support;

(5) Design of the to-be digital support in collaboration with the technological provider, based on the requirement identified;

(6) Assessment of the impact of the network and its digital support with a set of suitable KPIs [12]: these can assess clinical outcomes, such as quality of life or overall mortality, the impact of the network, such as the health migration rate, or the impact of the digital support, such as the number of requests uploaded on the system.

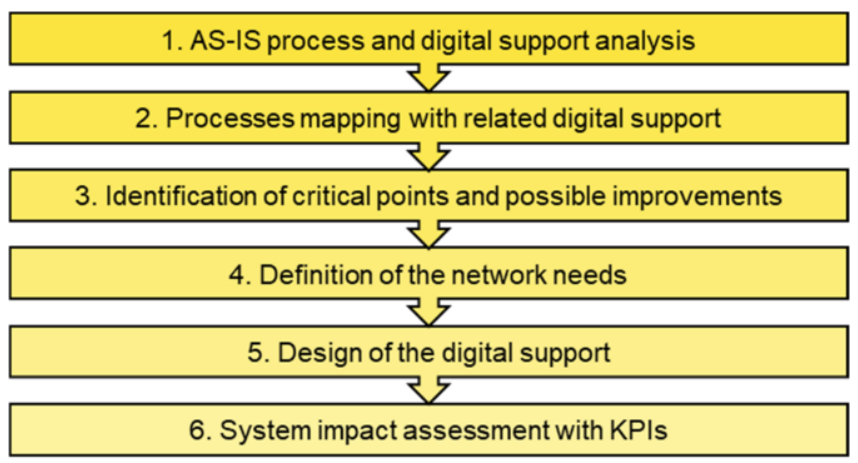

Figure 1. Methodological approach to (re-)organize a pathology network including its digital support.

Based on this methodology, focusing on the step nr. 5, we defined a general digital model for a general collaborative pathology network, pictured in figure 2. Actors involved are the User, a clinical center who requests a clinical service, a Provider, a clinical center who provides the requested clinical service, and the Mediator, a clinical center who manages the interaction between User and Provider, urging any of them if their conversation is not progressing. The underlying digital support should allow a User to submit a new clinical case by filling necessary data in the Clinical Module, and access 
the network archive to search clinical cases for care purposes. Then, the User creates and sends a request for a teleconsultation or any other clinical service through the Clinical service request form. The clinical service request should be automatically forwarded to a suitable Provider, based on his availability and expertise in the particular case. On the other hand, the Provider should be able to manage the Data sheet related to his clinical center, view his pending requests, possibly requesting additional information, and provide the Final report. The management of follow-up is the in charge of the User, who has to keep all the patient data updated. Additional transversal features ensure the collection of data and KPIs measurement for the assessment of the network and its digital support.

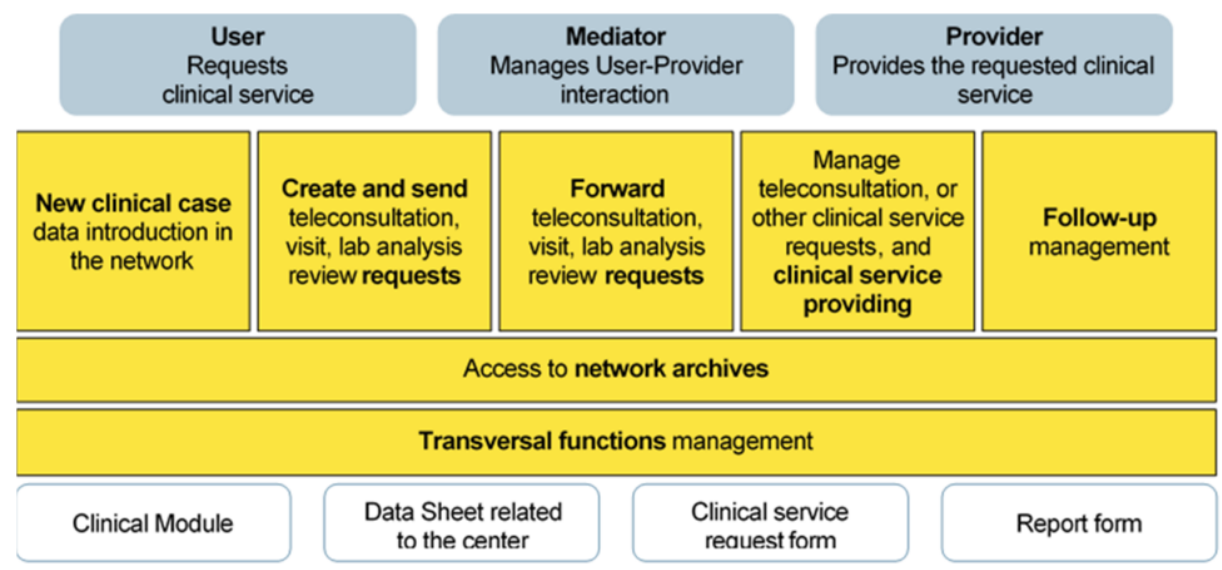

Figure 2. Schematic representation of the disease network features.

In addition to this, focusing on the step n.6 (see figure 1), we designed a KPIs panel to assess the impact of the pathology network and its digital support. The methodology adopted for the design of the KPIs panel is based on a classical "performance tree" with three classes of indicators: general indicators, describing general parameters of the functioning of a process; indicators for internal performances, related to the management of resources in terms of costs and quality, time and flexibility scopes; indicators for external performances, determining the value of the output for the client/user, again based on costs (prices), quality, time and flexibility. We identified effectiveness, governance, and efficiency as the Critical Success Factors (CSFs) for the analyzed network, aiming at determining the most relevant performance dimensions. Subsequently, we identified five parameters to select a sub-set of KPIs in order to obtain an easily manageable panel. Such parameters are: understandability (the KPI is easily understandable by those who need to use it), measurability (data for the KPI calculation are extracted in a simple way and at a low cost), meaningfulness (the KPI has an impact on the selected CSFs), frequency (the KPI is calculated on a period consistent with data variability), consistency (the KPI is objective, not subjective to personal interpretation). Eventually, a priority can be assigned to each indicator to identify the most relevant ones: KPIs fulfilling all the aforementioned parameters are assigned with a priority 1, KPIs fulfilling three or four parameters acquire priority 2, KPIs fulfilling less than 3 parameters were not included in the panel. As shown in table 1, the result is a set of indicators divided in three macro-areas: Effectiveness indicators, measuring the consistency of the organizational and technological solution with the purposes of the 
network; Governance indicators, assessing coordination and management features of the network with respect to the number of cases and service performances; and Efficiency indicators, evaluating the ability of the network to provide services optimizing available resources.

Table 1. KPIs Panel to monitor the impact of a collaborative pathology network and its digital support.

\begin{tabular}{|c|c|c|c|}
\hline Macro-area & Category & Indicator & Reason \\
\hline \multirow{7}{*}{ Effectiveness } & Quality of life & Quality of life level & $\begin{array}{l}\text { Determine the possible positive } \\
\text { impact of the network on the quality } \\
\text { of life of patients }\end{array}$ \\
\hline & \multirow[b]{2}{*}{$\begin{array}{l}\text { Clinical } \\
\text { appropriateness }\end{array}$} & Survival rate variation & $\begin{array}{l}\text { Determine the possible positive } \\
\text { impact of the network on the } \\
\text { survival of patients }\end{array}$ \\
\hline & & Consistency with guidelines & $\begin{array}{l}\text { Define the consistency with clinical } \\
\text { guidelines to ensure clinical } \\
\text { appropriateness and a better } \\
\text { healthcare process }\end{array}$ \\
\hline & \multirow{2}{*}{ Satisfaction } & Patients' satisfaction level & $\begin{array}{l}\text { Monitor patients' satisfaction with } \\
\text { the healthcare process }\end{array}$ \\
\hline & & Professionals' satisfaction level & $\begin{array}{l}\text { Monitor professionals' satisfaction } \\
\text { in the use of the network services }\end{array}$ \\
\hline & $\begin{array}{l}\text { Psychological impact } \\
\text { on patients }\end{array}$ & Psychological impact on patients & $\begin{array}{l}\text { Monitor the psychological impact } \\
\text { son the patients after their } \\
\text { involvement in the network }\end{array}$ \\
\hline & Health migration & Health migration rate & $\begin{array}{l}\text { Determine the possible positive } \\
\text { impact of the network and its digital } \\
\text { support on health migration in the } \\
\text { area covered by the network }\end{array}$ \\
\hline \multirow{6}{*}{ Governance } & \multirow{4}{*}{ Digital support use } & Nr. of cases uploaded & $\begin{array}{l}\text { Monitor the total volumes managed } \\
\text { by the network }\end{array}$ \\
\hline & & Nr. of cases uploaded per User & $\begin{array}{l}\text { Monitor the total volumes managed } \\
\text { by each User clinical center }\end{array}$ \\
\hline & & Nr. of teleconsultations provided & $\begin{array}{l}\text { Monitor the total volumes managed } \\
\text { by the network }\end{array}$ \\
\hline & & $\begin{array}{l}\text { Nr. of teleconsultations provided } \\
\text { per Provider }\end{array}$ & $\begin{array}{l}\text { Monitor the total volumes managed } \\
\text { by each Provider clinical center }\end{array}$ \\
\hline & \multirow{2}{*}{$\begin{array}{l}\text { Network service } \\
\text { performance }\end{array}$} & $\begin{array}{l}\text { Average time to provide } \\
\text { teleconsultations or any other } \\
\text { clinical service }\end{array}$ & $\begin{array}{l}\text { Monitor general service levels of the } \\
\text { network }\end{array}$ \\
\hline & & $\begin{array}{l}\text { Percentage of teleconsultations } \\
\text { or any other clinical service } \\
\text { provided within the average time }\end{array}$ & $\begin{array}{l}\text { Monitor general service levels of } \\
\text { Provider clinical centers }\end{array}$ \\
\hline \multirow{7}{*}{ Efficiency } & $\begin{array}{l}\text { Development and } \\
\text { maintenance costs }\end{array}$ & $\begin{array}{l}\text { Total development and } \\
\text { maintenance costs of digital } \\
\text { support }\end{array}$ & $\begin{array}{l}\text { Determine the total development } \\
\text { and maintenance cost of the digital } \\
\text { support }\end{array}$ \\
\hline & \multirow{3}{*}{$\begin{array}{l}\text { Health migration } \\
\text { costs }\end{array}$} & $\underline{\text { Missed productivity cost }}$ & \multirow{3}{*}{$\begin{array}{l}\text { Determine the possible saving due } \\
\text { to the reduction of health migration } \\
\text { rate enabled by the network }\end{array}$} \\
\hline & & $\underline{\text { Transportation costs }}$ & \\
\hline & & Accommodation costs & \\
\hline & $\begin{array}{l}\text { Psychological } \\
\text { support costs }\end{array}$ & Psychological support costs & $\begin{array}{l}\text { Determine the possible saving due } \\
\text { to the reduction of health migration } \\
\text { rate enabled by the network }\end{array}$ \\
\hline & \multirow[b]{2}{*}{$\begin{array}{l}\text { Clinical non- } \\
\text { appropriateness costs }\end{array}$} & Improper surgery costs & $\begin{array}{l}\text { Determine the cost of improper } \\
\text { surgeries }\end{array}$ \\
\hline & & $\begin{array}{l}\text { Improper histological analysis } \\
\text { cost }\end{array}$ & $\begin{array}{l}\text { Determine the cost of improper } \\
\text { histological analyses, causing an } \\
\text { increase in additional evaluation } \\
\text { processes }\end{array}$ \\
\hline
\end{tabular}


The panel of KPIs, together with the reason for their selection, is reported in table 1; additional parameters are the measurement period, the target and the priority, which can be defined based on the specific network considered. Some indicators are assessed with suitable questionnaires that can be found in literature and selected for each specific application, such as Quality of life level, Patients satisfaction level, Professionals satisfaction level and Psychological impact on patients. Other KPIs need a set of data extracted from the system, such as Survival rate variation, Number of cases uploaded, Number of teleconsultations provided per Provider, Average time to provide teleconsultations or any other clinical service, etc.

In the next paragraph, we will describe how the general methodology to design a digital support of a collaborative pathology network, together with a set of KPIs to assess the impact of the pathology network and its digital solution, was applied to the case of the Italian Rare Cancer Network in the framework of the "Italian Rare Cancer Network: Process monitoring and System Impact Assessment” Project.

\section{Use Case: Italian Rare Cancer Network}

Rare cancers include some families of adult solid cancers, all childhood cancers and a group of hematological neoplasms, with an incidence of 6/100.000 cases; however, they account for the $20 \%$ of all new cancer cases among EU Member States [13]. This area can be substantially improved from the effectiveness and efficiency point of view by the collaboration of professionals: in the framework of European Reference Networks (ERNs), the Italian Rare Cancer Network was established as an institutional network in 2017 as an evolution of the former professional network, cooperating with the Italian Ministry of Health and Regional Healthcare Systems in a Hub-and-Spoke configuration.

The project "Italian Rare Cancer Network: Process monitoring and System impact Assessment" was funded by the Italian Ministry of Health in 2017 with the purpose of re-organize the existing Rare Cancer Network, design a suitable related digital support and a panel of indicator to evaluate their impact. The ultimate target of the network is to improve quality of life of patients affected by rare cancers with the enhancement of the healthcare process they are involved in; for this purpose, it is paramount to foster expertise throughout the Country, share clinical cases among hubs and spokes clinical centers, optimize healthcare resources, define shared clinical guidelines, and organize training for professionals $[14,15]$.

Recalling the methodology presented in the previous chapter, we first analyzed the current process for the management of patients affected by rare cancers, obtaining the process mapping with BPMN as a result. Different scenarios were identified, based on the possible needs for each clinical case, such as: supply of a teleconsultation, supply of a visit, supply of a histological review, a combination of them possibly with the request of additional information or a side scenario in which the patient goes independently to the Provider center, bypassing the Network system.

Then, we identified the weak points of the current organization, discovering that one of the main limitations of the network is related to the obsolescence of the digital support. For that reason, according to the methodology described in this paper, we focused on defining the requirements for the new digital support for the Network. Functional requirements should allow all the actors involved in the Network to perform particular actions as described in figure 2 , such as the request of teleconsultation by a User via a suitable teleconsultation form, containing all the patients personal and clinical data, the 
possibility for the Mediator to forward the request to a suitable Provider, the management of requests in charge of a Provider and the upload of the report together with possible supplementary reports or images in case of additional visits, etc. Non-functional requirements include, but are not limited to: coherence with Regional and National Healthcare Information Systems, scalability in case of Network growth with the addition of new centers, reliability for the continuous operation of the system, data integrity in case of system failure, security and privacy for data management in a cross-center configuration, etc.

The following step was the implementation of the digital support of the Network. Three possibilities of implementation were evaluated: the first one meant to extend a system already used by a center of the Network, being it already tested and wellestablished, but with possible privacy compliance issues. The second one intended to readapt the existing Network tool, again already tested and well-established as well as potentially consistent with the Network requirements; however, necessary adjustments could be very expensive and time-consuming. Therefore, we decided to select the third one: the implementation of an ad-hoc system completely consistent with functional and non-functional Network requirements.

Finally, in order to assess the impact of the Network and its digital support, we selected the suitable KPIs from the panel already described in table 1. In particular, we decided to consider only priority 1 indicators, corresponding to those that can be measured during the project timeframe. As reported in table 2, the majority of them are considered for this first assessment process. Priority 2 was assigned to Survival rate variation, Improper surgery costs and Improper histological analysis cost because measurability and frequency parameters were not fulfilled. Hereafter, we will present the measurement process for some of the selected KPIs.

Quality of life level is assessed via the QLQ-C30 (version 3.0) questionnaire promoted by the European Organization for Research and Treatment of Cancer (EORTC), and administered via the Network digital tool. The Project teams expects an improvement of quality of life for patients involved in the Italian Rare Cancer Network. The same outcome is expected for other indicators assessed with questionnaires, such as Patients satisfaction level and Professionals satisfaction levels, evaluated with the standard PSQ-18 and CSQ-8 questionnaires respectively.

Another important group of indicators is the Health migration costs: one of the aims of the Italian Rare Cancer Network is to limit health migration, not only to improve the quality of the healthcare process and the life of patients. In particular, Missed productivity cost is calculated as the daily salary multiplied by unpaid absence days for all the patients of the Network; Transportation costs is calculated as the cost of fuel multiplied by the distance covered and the number of travels for all patients; Accommodation costs is calculated as the standard cost for a hotel room multiplied by the number of overnight stays for every journey. The total amount of expenditure should be reduced by avoiding travels for healthcare reasons, thanks to services provided by the Network. 
Table 2. KPIs panel developed during the project "Italian Rare Cancer Network: Process monitoring and System impact Assessment".

\begin{tabular}{|c|c|c|c|}
\hline Macro-area & Category & Indicator & Priority \\
\hline \multirow[t]{7}{*}{ Effectiveness } & Quality of life & Quality of life level & 1 \\
\hline & \multirow[t]{2}{*}{ Clinical appropriateness } & Survival rate variation & 2 \\
\hline & & Consistency with guidelines & 1 \\
\hline & \multirow[t]{2}{*}{ Satisfaction } & Patients' satisfaction level & 1 \\
\hline & & Professionals' satisfaction level & 1 \\
\hline & $\begin{array}{l}\text { Psychological impact on } \\
\text { patients }\end{array}$ & Psychological impact on patients & 1 \\
\hline & Health migration & Health migration rate & 1 \\
\hline \multirow[t]{6}{*}{ Governance } & \multirow[t]{4}{*}{ Digital support use } & Nr. of cases uploaded & 1 \\
\hline & & Nr. of cases uploaded per User & 1 \\
\hline & & Nr. of teleconsultations provided & 1 \\
\hline & & Nr. of teleconsultations provided per Provider & 1 \\
\hline & \multirow[t]{2}{*}{$\begin{array}{l}\text { Network service } \\
\text { performance }\end{array}$} & $\begin{array}{l}\text { Average time to provide teleconsultations or any } \\
\text { other clinical service }\end{array}$ & 1 \\
\hline & & $\begin{array}{l}\text { Percentage of teleconsultations or any other clinical } \\
\text { service provided within the average time }\end{array}$ & 1 \\
\hline \multirow[t]{7}{*}{ Efficiency } & $\begin{array}{l}\text { Development and } \\
\text { maintenance costs }\end{array}$ & $\begin{array}{l}\text { Total development and maintenance costs of digital } \\
\text { support }\end{array}$ & 1 \\
\hline & \multirow[t]{3}{*}{ Health migration costs } & Missed productivity cost & 1 \\
\hline & & Transportation costs & 1 \\
\hline & & Accommodation costs & 1 \\
\hline & $\begin{array}{l}\text { Psychological support } \\
\text { costs }\end{array}$ & Psychological support costs & 1 \\
\hline & \multirow{2}{*}{$\begin{array}{l}\text { Clinical non- } \\
\text { appropriateness costs }\end{array}$} & Improper surgery costs & 2 \\
\hline & & Improper histological analysis cost & 2 \\
\hline
\end{tabular}

\section{Conclusion}

The methodology we presented to design a digital support of a collaborative pathology network and a set of KPIs to assess the impact of the pathology network and its digital solution is based on well-established procedures described in literature. We believe it can be applied to any kind of collaborative pathology network to obtain similar results, considering the specificity of each disease. Moreover, the definition of a panel of KPIs for the assessment of the impact of a collaborative pathology network and its digital support is paramount to ensure the best quality of the healthcare process and the identification of possible improvements. The next step of the Project will be the collection of data from the platform to assess the impact of the Network with the new digital system and compare the previous situation. In parallel, a review of the Network organization is ongoing, possibly resulting in impacts on the indicators selected.

\section{Acknowledgments}

The project "Italian Rare Cancer Network: Process monitoring and System Impact Assessment" is supported by the Italian Ministry of Health (Grant No. RF-201602363386). The authors would like to thank the project coordinator Fondazione IRCCS Istituto Nazionale dei Tumori di Milano and the partner Istituto Europeo di Oncologia. 


\section{References}

[1] Prades J, Morando V, Tozzi VD, Verhoeven D, Germà JR, Borras JM. Managing cancer care through service delivery networks: The role of professional collaboration in two European cancer networks. Health Services Management Research. 2018;31(3):120-129. doi:10.1177/0951484817745219

[2] Camarinha-Matos L, Bénaben F, Picard W. Risks and Resilience of Collaborative Networks: 16th IFIP WG 5.5 Working Conference on Virtual Enterprises, PRO-VE 2015, Albi, France, October 5-7, 2015

[3] Thimm H, Rasmussen KB. Information Support Services for Intermediation Tasks of Collaborative Networks. J. UCS. 2010;16:1776-1800

[4] Lenz R, Reichert M. IT Support for Healthcare Processes. In: Proceedings 3rd International Conference on Business Process Management (BPM'05), 5 - 8 Sep 2006, Nancy, France. pp. 354-363

[5] Buranarach M. et al. (2011). Design and Implementation of an Ontology-Based Clinical Reminder System to Support Chronic Disease Healthcare, IEICE Transactions on Information and Systems, pp. 432-439

[6] Botheju WMD. "Smart eHealth" - A Holistic Approach to Implementing an Integrated Healthcare Information System (HIS) in Sri Lanka. SLIIT, 2018

[7] Reinhard C et al. The European Reference Network for Rare Neurological Diseases. Front Neurol. 2021;11, 616569. doi: 10.3389/fneur.2020.616569

[8] Bassanese G. et al. The European Rare Kidney Disease Registry (ERKReg): objectives, design and initial results. Orphanet J Rare Dis. 2021;16:251. doi:10.1186/s13023-021-01872-8

[9] Hammer M, Champy J. Reengineering the Corporation: A Manifesto for Business Revolution. Harper Business, New York, NY, 1993

[10] Locatelli P, Cirilli F, Panno E, Provenzano S, Sanfilippo R, Casali PG. Digital Support for a Hub-andSpoke Disease Network. IADIS International Conference e-Health, 2020.

[11] Osterwalder A, Pigneur, Y. Business model generation: A handbook for visionaries, game changers, and challengers. Hoboken: Wiley; 2010

[12] Locatelli P, Facchini R, Moser R, Gastaldi L, Corso M, Sini E, Torresani M. Effectively introducing mobile solutions in hospitals: The importance of process perspective and KPIs. Proceedings - IEEE Symposium on Computer-Based Medical Systems. CBMS 2014. 2014: 417-420

[13] Casali PG, Trama A. Rare Cancers Agenda 2030. EU Joint Action on Rare Cancers, 2019

[14] Carmeli B, Casali P, Goldbraich A, Goldsteen A, Kent C, Licitra L, Locatelli P, Restifo N, Rinott R, Sini E, Torresani M, Waks Z. Evicase: An evidence-based case structuring approach for personalized healthcare. Stud Health Technol Inform. 2021;180:604-8

[15] Waks Z, Goldbraich E, Farkash A, Torresani M, Bertulli R, Restifo N, Locatelli P, Casali P, Carmeli B. Analyzing the "careGap": Assessing gaps in adherence to clinical guidelines in adult soft tissue sarcoma. Stud Health Technol Inform. 2013;186:46-50 